ISSN 1518-3483

Licenciado sob uma Licença Creative Commons

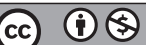

\title{
Saberes da prática na formação: representações sociais de alunas de Pedagogia
}

\author{
Knowledge of practice in formation: social \\ representations of students of Pedagogy
}

\begin{abstract}
Márcia Gentile ${ }^{[a]}$, Rita de Cássia Pereira Lima ${ }^{[b]}$, Tarso Mazzotti ${ }^{[c]}$
[a] Mestre em Educação pelo Programa de Pós-Graduação em Educação da Universidade Estácio de Sá, psicopedagoga do Centro Integrado Lauro de Oliveira Lima, Rio de Janeiro, RJ - Brasil, e-mail: marciagentile@hotmail.com

[b] Doutora em Educação pela Université René Descartes - Paris V, docente do Programa de PósGraduação em Educação da Universidade Estácio de Sá, Rio de Janeiro, RJ - Brasil, e-mail: ritalima@netsite.com.br

[c] Doutor em Educação pela Universidade de São Paulo (USP), Docente do Programa de PósGraduação em Educação da Universidade Estácio de Sá, Rio de Janeiro, RJ - Brasil, e-mail: tarsomazzotti@uol.com.br
\end{abstract}

\section{Resumo}

O objetivo deste trabalho é investigar representações sociais de alunos de Pedagogia sobre saberes da prática. Esta pesquisa fundamenta-se na teoria moscoviciana das representações sociais e em estudos no campo da formação de professores. A pesquisa foi realizada com 34 alunos do último ano de Pedagogia, 10 de uma universidade privada 
e 24 de uma universidade pública do Estado do Rio de Janeiro. Foram realizados quatro grupos focais, dois em cada universidade. Para provocar discussões nos grupos, utilizou-se como recurso inicial um texto com estilo de reportagem que descrevia uma experiência de formação em serviço. A análise do material apoiou-se na análise de conteúdo temática. Os resultados revelam três temas articulados: relação teoria e prática, saberes da prática e expectativas sobre o curso de Pedagogia. Os resultados mostram um núcleo figurativo das representações sociais dos alunos sobre saberes da prática que destaca a dissociação entre teoria e prática na formação. Esse sentido pode ser condensado por uma metonímia observada na análise do material: "um palco onde se encena uma peça em que o professor é o ator". No 'palco', em que seria portador da teoria necessária para 'encenar', o professor faz uma 'adaptação' das diferentes realidades escolares e dos diversos públicos de alunos. Assim, o professor-ator encena sua prática e, a cada dia, o 'espetáculo' pode ser diferente, dependendo do 'cenário' e do 'público'. Ao 'adaptar' e 'encenar' o professor vai construindo os 'saberes da prática' em seu cotidiano de trabalho, que tende a se afastar do conhecimento científico adquirido na formação.

Palavras-chave: Pedagogia. Representações sociais. Saberes da prática.

\section{Abstract}

The objective of the work is to investigate social representations of students of Pedagogy about knowledge of practice. It is based on the Moscovician theory of social representations. The research was made with 34 students in the final year of the course of Pedagogy, 10 from a private University and 24 from a public University of the State of Rio de Janeiro. Four groups were made, two in each University. In order to arouse discussions in the groups it was used as initial resource a reporting style text that described an experience of formation in service. The analysis of the material supported itself in the analysis of thematic content. The results showed a figurative nucleus of the social representations that distinguishes the dissociation between theory and practice in the formation. This meaning can be condensed by a metonymy observed in the analysis of the material: "a stage where it is played a play in which the teacher is the actor". On the 'stage' in which he would be the bearer of the theory necessary 'to play', the teacher makes an 'adaptation' to the different school realities and to the different audiences of students. Thus, the teacher-actor plays his practice and each day the 'show' can be different, depending on the 'scenery' and on the 'audience'. In 'adapting' 
and 'playing' the teacher builds the 'knowledge of practice' in his daily life of work, which tends to get away from the scientific knowledge acquired in the formation.

Keywords: Pedagogy. Social representations. Knowledge of practice.

\section{Introdução}

A preocupação com a formação de professores não é um fato novo na área da educação, visto que tem interessado vários pesquisadores. Em relação ao curso de Pedagogia, na década de 1990 o tema estava diretamente relacionado à formação de professores para os anos iniciais do ensino fundamental, como relatam André et al. (1999) e Andrade (2007). Andrade (2007) realizou um levantamento de dissertações e teses sobre o tema depois desse período e constatou que houve um crescimento considerável de publicações ao longo dos anos. A maior parte dos trabalhos privilegiou os cursos de formação, seus currículos, seus projetos pedagógicos, a relação teoria-prática, dentre outros.

Aguiar et al. (2006) mostram que há visões controversas acerca das Diretrizes Curriculares Nacionais, para o curso de graduação em Pedagogia (BRASIL, 2006), que normatizam as carreiras de bacharel e licenciado. Eles ressaltam que aquelas diretrizes estabelecem um novo tempo e assinalam novos debates no campo da formação profissional. De acordo com os autores, as diretrizes curriculares (DC) contribuíram para ampliar a compreensão da complexidade do campo da Pedagogia e os desafios teórico-práticos que as universidades estão enfrentando para concretizar a reforma proposta, porque a formação nesse curso necessita garantir a articulação entre a docência, a gestão educacional e a produção de conhecimento na área da educação.

Mesmo com debates frequentes, acentuam-se as controvérsias em torno da formação oferecida pelo curso de Pedagogia, sobretudo em relação à articulação teoria e prática. Diversos autores (ALMEIDA; 
BIAJONE, 2007; DUARTE, 2003; LIBÂNEO, 2006; SAVIANI, 2007, dentre outros) estão de acordo com as afirmações publicadas por Durham (2006) no sentido de que "as Diretrizes deram um passo atrás". Os autores acreditam que estas foram mal formuladas, fornecendo interpretações variadas, já que não está claro qual será a função da Pedagogia e como será seu campo de estudo e formação. Eles questionam a função do curso de Pedagogia e sua identidade enquanto campo de conhecimento.

Almeida e Biajone (2007), referindo-se a Tardif (2002), mostram que os cursos de formação, na esfera universitária, não têm conseguido formar adequadamente o profissional de educação por estarem centrados no saber acadêmico/teórico, privilegiando os saberes disciplinares. Nesse caso, a teoria é vista como um conjunto de conhecimentos acadêmicos/ científicos e a prática seria a aplicação da teoria, enfatizando-se assim a divisão entre teoria e prática.

De acordo com Tardif (2002 apud ALMEIDA; BIAJONE, 2007, p. 286), "os saberes disciplinares correspondem aos diversos campos de conhecimento sob a forma de disciplina - são saberes sociais definidos e selecionados pela instituição universitária e incorporados na prática docente". A proposta de tal autor sugere que as pesquisas desenvolvidas na área educacional se concentrem na investigação dos saberes profissionais que os professores utilizam no seu cotidiano, a partir de atividades e realidades do trabalho do professor. Os saberes profissionais são considerados pelo autor como "o estudo do conjunto dos saberes utilizado realmente pelos profissionais em seu espaço de trabalho cotidiano para desempenhar todas as suas tarefas" (TARDIF, 2002 apud ALMEIDA; BIAJONE, 2007, p. 286). O que estamos denominando de "saberes da prática" se aproxima da ideia de "saberes profissionais" proposta por Tardif.

Segundo Duarte (2003), autores como Perrenoud (2002), Schön (2000), Gauthier (1998), Shulman (2004), Lessard (2006) e Lelis (2001) estão em consonância com Tardif, ao salientarem a necessidade das universidades modificarem a sua forma de trabalhar, já que estão organizadas por formas tradicionais de ensino e também por terem responsabilidade social com a formação de professores e com a educação do país. 
Duarte (2003), porém, contesta os autores citados por desvalorizarem o conhecimento científico/teórico, dando ênfase aos saberes profissionais com características tácita, pessoal, particular e subjetiva na formação de professores. Ele ainda deixa claro que Schön (2000) influenciou o ideário desse grupo, quando traz à tona o modelo de racionalidade prática, em que a ideia central envolve o aprendizado com as experiências pessoais de cada um, sendo uma reflexão na ação.

Franco, Libâneo e Pimenta (2007), Libâneo (2006) e Saviani (2007) mostram que o movimento das entidades representativas dos profissionais de educação defendeu a proposta de uma política de formação baseada na necessidade de organização de um núcleo comum nacional para os cursos de formação. Essa base é a docência, que foi incorporada nas DC para o curso de Pedagogia (BRASIL, 2006).

Entretanto, na visão de Franco, Libâneo e Pimenta (2007), essa forma compromete a formação do profissional de educação porque esvazia os estudos sistemáticos de educação e descaracteriza o pedagogo. Alunos egressos dos cursos de Pedagogia não estudaram a teoria e a prática da Pedagogia, visto que na formação foram oferecidas disciplinas das ciências-mãe para falar de educação sem dar conta dos fenômenos educativos que são importantes para quem vai dar aula. Ou seja, alguns cursos de educação oferecidos atualmente reduziram a formação do pedagogo à docência, suprimindo em algumas instituições a formação de especialistas ou pedagogos. Em consequência, houve baixa de qualidade e fragmentação das disciplinas oferecidas voltadas para prática docente (LIBÂNEO, 1999).

A especificidade do campo científico e profissional da Pedagogia é, portanto, um objeto de intensa polêmica. Para Franco, Libâneo e Pimenta (2007, p. 69), o objeto da Pedagogia "como ciência da educação é o esclarecimento reflexivo e transformador da práxis educativa". A intencionalidade dessa reflexão é mais abrangente porque o papel que a Pedagogia deve desempenhar é o de refletir para transformar, refletir para conhecer, para compreender e constituir meios para modificar as práticas educativas. Entretanto, isso não está acontecendo porque, após a homologação 
das atuais DC, o curso de Pedagogia passou a ser identificado como curso para docência nas séries iniciais do ensino fundamental.

Franco, Libâneo e Pimenta (2007) defendem um curso específico de Pedagogia como campo teórico, consolidando a formação de profissionais que precisem aperfeiçoar a reflexão e a pesquisa sobre a educação e o ensino da Pedagogia. Ambos podem encontrar amparo em Lessard (2006, p. 223) quando este afirma:

nos anos por vir os formadores de docentes têm um papel crucial a desempenhar na construção da relação dos jovens docentes com a ciência e a pesquisa. A pior coisa seria os formadores desenvolverem nos jovens docentes uma relação reverencial e dócil com as ciências humanas e sociais e estes passarem a vê-las como referência última para fundamentar e regular sua prática. Fica então evidente que o papel dos formadores de docentes é de estimular a reflexão.

As posições de alguns teóricos mencionados demonstram não haver acordo sobre como deve ser a formação de professores, talvez por não apresentarem um modo de fazer, mas um discurso político educacional. Isso porque as propostas de formação centradas no desenvolvimento profissional em serviço foram e são descartadas em nome do "pensamento crítico". No geral, essas críticas não apresentam propostas para melhorar a qualidade da formação desses professores, o que lhes confere um cunho político em detrimento do educacional, daí suas análises e críticas quase sempre ficarem no campo do ideal e não do real, ou do prático ou realizável.

Em suma, não há consenso a respeito dos conhecimentos que seriam adequados à formação de professores. Diante disso, algumas questões podem ser colocadas: em que medida essa formação está contribuindo para a atividade profissional na área, com base na visão dos alunos? Que saberes os alunos de Pedagogia constroem sobre a prática em sua formação? Como eles pensam a articulação teoria e prática nessa formação? Que saberes eles constroem a partir da própria prática, independentemente da formação? Nesse aspecto, faz-se necessário desvendar como esses alunos estão elaborando significados sobre os saberes da prática. 
Justifica-se, assim, a escolha do referencial teórico-metodológico das representações sociais. Conforme Jodelet (2001, p. 22), essas representações: "são uma forma de conhecimento social elaborada e partilhada tendo uma visão prática e concorrendo para a construção de uma realidade comum a um conjunto social". As RS são expressões de comportamentos de indivíduos no contexto social do qual fazem parte e esses comportamentos as instituem e são instituídos por elas.

Podemos dizer que as representações sociais são caracterizadas, segundo Madeira (2001, p. 127), como: "fenômenos complexos que dizem respeito ao processo pelo qual o sentido de um objeto é estruturado pelo sujeito, no contexto de suas relações". Assim, entendemos que na relação com o outro o sujeito constrói o seu sentido com o objeto, da mesma forma que é construído por ele. Para a autora, "a aplicação das representações sociais no campo da educação permite tomar objetos de pesquisa no dinamismo que os constitui e lhes dá forma" (MADEIRA, 2001, p. 126). Esses objetos são constituídos de diferentes sentidos, mas não isolados e sim ligados a uma configuração, integrando o objetivo e o subjetivo.

Por conseguinte, ao pensarmos nos saberes da prática no âmbito da formação de professores, podemos dizer que é uma construção social e histórica que está em permanente movimento, sendo constituída por múltiplas relações, porque há marcas de grupos sociais que estão em posições diferentes. Os alunos de Pedagogia podem assim construir representações sobre os saberes da prática durante sua formação, sendo o curso um espaço de interações privilegiado que propicia essa construção. Nesse processo, o sujeito também se constrói, se reconhecendo para ser reconhecido.

Com base em tais fundamentos, o estudo tem como objetivo investigar representações sociais de alunos de Pedagogia sobre saberes da prática. As representações sociais dos alunos a respeito do tema podem contribuir com reflexões para que a formação na universidade não tenda a estabelecer dicotomias entre as dimensões teórica e prática, favorecendo ao futuro profissional da área um trabalho que as articule melhor. 


\section{Metodologia}

A pesquisa de campo foi realizada no ano de 2009 em duas universidades do Estado do Rio de Janeiro. A primeira, privada (universidade A), propõe uma formação mais ampla, não formando somente professores das séries iniciais do ensino fundamental. De acordo com os objetivos estabelecidos para o curso de Pedagogia, o aluno poderá agir em diversas organizações escolares: instituições educacionais de diferentes níveis e modalidades de ensino, como escolas de educação infantil, ensino fundamental e ensino médio; organizações não escolares: em espaços educativos de instituições empresariais e de organismos públicos ou privados; e em organizações do terceiro setor (ONGs e demais organizações da sociedade civil), em especial, nos setores ligados às atividades de planejamento, coordenação, avaliação e gestão de projetos educacionais. Os alunos que participaram da pesquisa encontravam-se cursando um currículo transitório. Procurando atender às DC para o curso de Pedagogia (BRASIL, 2006), a universidade incluiu formação voltada para a pedagogia empresarial, gestores, coordenadores e supervisores dentre outros, ou seja, essa universidade construiu um currículo amplo.

Já a segunda universidade, pública (universidade B), propõe a formação de professores para o ensino fundamental de crianças, jovens e adultos, com atenção para a inclusão dos alunos portadores de necessidades educativas especiais e, também, atuação em atividades específicas de educação infantil, de zero a seis anos, e em empresas, conselhos, instituições governamentais e movimentos sociais. Essa universidade, desde 1999, vinha modificando a grade curricular do curso de Pedagogia, a partir de debates, encontros e seminários de educação. Havia intenção de mudança de estrutura curricular atendendo aos modos de formação em serviço. No entanto, quando as novas DC foram homologadas esse processo foi interrompido. As alunas que participaram da pesquisa cursavam também um currículo transitório, com o objetivo de atender às exigências declaradas nas novas DC, porém, a instituição manteve um único objetivo: formação de professores para o ensino fundamental (na formação do magistério, nesse período transitório, e também magistério para educação infantil). 
A diferença entre a grade curricular da universidade A e da B são as disciplinas referentes ao Ciclo de Formação em Gestão, Escolares e Não Escolares, Empresarial. No mais, as matérias oferecidas parecem similares.

Os sujeitos da pesquisa foram 34 alunos da classe do último período do curso de Pedagogia: 10 da universidade A e 24 da universidade B. Todos os alunos da classe foram convidados a participar do estudo. Aos que aceitaram, primeiramente, foi aplicado um formulário de caracterização, buscando-se obter dados pessoais e socioprofissionais. Em seguida, foram formados grupos focais (GF), sendo dois realizados na universidade $A$ e dois na universidade $B$, com intenção de que as discussões entre os alunos permitissem investigar possíveis representações sociais sobre saberes da prática que eles vêm construindo. A técnica de grupo focal foi considerada adequada para investigar o assunto, pois, segundo Rizzini, Castro e Sartor (1999, p. 67), "possibilita a obtenção de dados qualitativos sobre opiniões, atitudes e valores relacionados a um tema específico".

Nos grupos focais, como recurso para provocar discussões, foi utilizado um texto fictício, com estilo de reportagem, descrevendo uma experiência de formação em serviço. Esse texto, exposto no Anexo, surgiu a partir da proposta do livro de Lauro Oliveira Lima, originalmente aplicada no Ceará, na década de 1950.

Fundamentalmente, Lauro de Oliveira Lima denuncia que novos processos didáticos, desenvolvidos a partir de descobertas científicas recentes em relação ao desenvolvimento humano, não são sequer conhecidos pela maioria dos educadores. Para o autor, esse é o grande problema da educação brasileira: a falta de uma didática que permita a formação adequada de indivíduos que serão capazes de planejar o futuro. Ele ainda afirma: "as disciplinas tradicionais do currículo, por mais bem administradas que sejam, não formam, por si mesmas, professores. A 'formação' resulta sempre de treinamento real" (LIMA, 1966, p. 54). Portanto, podemos dizer que não basta um indivíduo estudar psicologia, sociologia, metodologia de ensino, filosofia da educação, para se tornar um profissional da área. É necessário que ele, na prática da aprendizagem, "viva situações 
profissionais, interpretadas e analisadas à luz destas disciplinas, para ganhar consciência e proficiência como mestre" (LIMA, 1966, p. 54).

Pode-se dizer que a proposta de formação apresentada no texto em estilo de reportagem, baseada nas ideias de Lauro de Oliveira Lima publicadas em 1966, se aproxima das propostas de autores como Tardif (2002), Perrenoud (2002), Schön (2000), dentre outros, por ser centrada no desenvolvimento profissional em serviço. Observamos que a reportagem provocou reflexão sobre a formação e a maioria dos sujeitos da pesquisa pareceu estar de acordo com a formação em serviço. Parecem sugerir que essa forma é adequada para construir o diálogo que falta entre a teoria e a prática.

\section{Análise do material}

A análise de dados, segundo Alves-Mazzotti e Gewandsznajder (2000, p. 170), "se faz através de um processo continuado em que se procura identificar dimensões, categorias, tendências, padrões, relações, desvendando-lhes o significado". Nesse sentido, para análise do material obtido por meio dos grupos focais, foi utilizado o procedimento de análise de conteúdo, definido por Bardin (1977, p. 42) como:

um conjunto de técnicas de análise de comunicação visando obter, por procedimentos sistemáticos e objetivos de descrição do conteúdo das mensagens, indicadores (quantitativos ou não) que permitam a inferência de conhecimentos relativos às condições de produção/ recepção destas mensagens.

Para atingirmos os significados declarados e ocultos no material, usamos a técnica da análise temática com intenção de buscar a presença de determinados temas que indicassem valores de referência e modelos de comportamento presentes no discurso das alunas. De acordo com Bardin (1977, p. 105), “o tema é a unidade de significação que se liberta naturalmente de um texto analisado segundo critérios relativos à teoria que serve de guia à leitura". 
A análise das falas começou por várias leituras flutuantes das transcrições e escuta das gravações em áudio. Em seguida, foram identificados três temas-chave relacionados: "Relação Teoria e Prática", "Saberes da Prática" e "Expectativas sobre o Curso de Pedagogia", para os quais foram inferidas categorias e subcategorias.

\section{Discussão}

A análise de conteúdo temática mostrou discursos similares nos quatro grupos focais. Verificamos que os GFs 1, 2 e 4 expressam a ideia de que a teoria/conhecimentos recebidos na universidade precisam ser adaptados à sala de aula, pois os alunos não conseguem estabelecer uma relação entre a teoria e a prática na realidade escolar. No que se refere ao GF 3, percebemos uma especificidade. Esse grupo, concentrado em duas líderes, se mostrou dividido quanto a essa questão: uma parte defendeu que a prática estava intrínseca à teoria e a outra concordou que deve acontecer adaptação da teoria à realidade. Ou seja, no GF 3 não houve consenso quanto à relação teoria e prática e definição dos saberes da prática. Uma investigação mais extensa talvez permita apreender claramente a representação social que coordena e condensa os discursos acerca daqueles saberes e as teorias que o grupo considera pertinentes.

Nos GFs 1, 2 e 4, as alunas utilizaram expressões como: ressignificar sua ação; reelaborar a atividade, vivendo, experimentando; aprender na prática, dentre outras, para salientar como constroem os saberes da prática. As alunas deixam claro que ao adaptar a teoria estão modificando, reorganizando, sua base teórica, que pode estar sendo construída pelo que consideram ser mais adequado quanto à maneira de um professor agir em sala de aula. Nesse sentido, podem fazê-lo sem uma lógica científica, seguindo a filosofia colocada pela escola ou buscando modelos de professores que já tiveram em sua vida escolar.

Para melhor compreender esses resultados à luz das representações sociais foi adotada a abordagem processual, ou seja, os processos 
de objetivação e ancoragem foram utilizados para investigar como os sujeitos da pesquisa constroem representações sociais sobre os saberes da prática. A objetivação define-se como: "transformar algo abstrato em algo concreto, transferir o que está na mente em algo que exista no mundo físico"; e ancoragem significa "transformar o não-familiar em familiar" ou transformar ideias estranhas em familiares, classificar, dar sentido ao objeto (MOSCOVICI, 2003, p. 61). A partir da indissociabilidade entre objetivação e ancoragem podemos entender como um objeto tem significações para o sujeito. Explicaremos esses dois processos por meio da identificação da metáfora (MAZZOTTI, 1998) que coordena e condensa o discurso das participantes.

A Figura 1 sintetiza a análise apresentada. Esse esquema explicita o núcleo figurativo da representação social sobre saberes da prática dos GFs 1 e 2, da universidade privada, e do GF 4 da universidade pública. Tal esquema foi elaborado com base na fala de uma estudante do GF 2, que condensa o significado do discurso das alunas desses três grupos:

é que nem palco, você está aprendendo na teoria e o que acontece na prática. [...] você absorve muita teoria [...] não sabe como é o cenário, você acaba o período absorvendo o que você quer, e depois [...]. O palco falou isso aqui, aquela marca não pode apertar tanto, onde tem que mexer é aqui, aqui não pode mexer, aqui não tem nada, na verdade é isso.

No esquema apresentado são observadas duas metonímias, ${ }^{1}$ "professor como se fosse um ator" e "aula como se fosse um roteiro de teatro", uma vez que a atividade docente é um trabalho como o do ator e o roteiro de aula é análogo ao de teatro. No 'palco' em que seria portador da teoria/texto/script necessários para 'encenar', o professor faz uma 'adaptação' às diferentes realidades escolares e aos diversos públicos de alunos. Assim, o professor-ator encena sua prática e, a cada dia, o 'espetáculo’ pode ser diferente,

1 Na análise retórica, o tema, o que se quer resignificar ou significar, é comparado (analogia) com o foro, o conhecido, do qual se selecionam alguns de seus significados. Caso o tema e o foro sejam diferentes em gênero ou espécie, tem-se uma metáfora; quando análogos, obtém-se uma metonímia. 


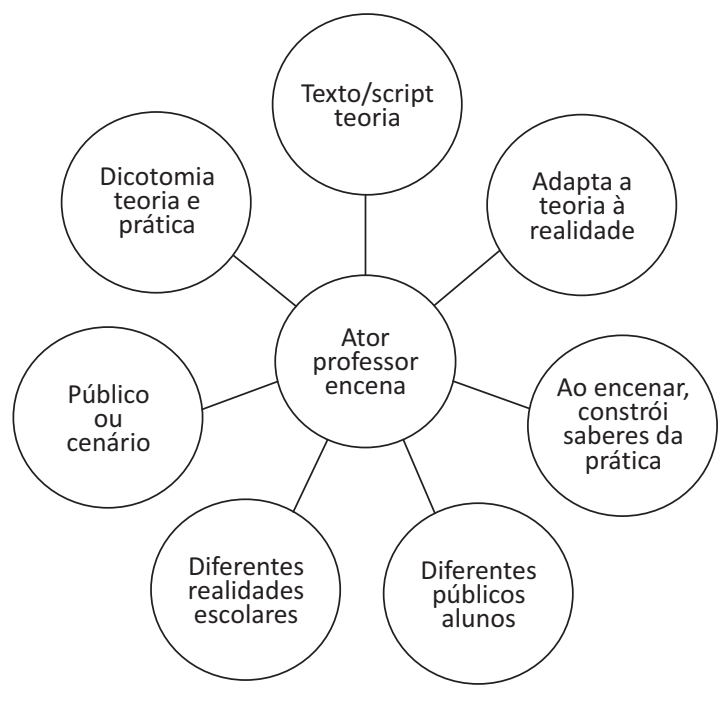

Figura 1 - Esquema do núcleo figurativo da representação social, dos grupos focais 1, 2 e 4, sobre saberes da prática

Fonte: Dados da pesquisa.

dependendo do 'cenário no palco' e do 'público'. Ao 'adaptar' e 'encenar', o professor vai construindo os 'saberes da prática' em seu cotidiano de trabalho, que tende a se afastar do conhecimento científico adquirido na formação. Dessa forma, podemos fazer a seguinte analogia: texto/script da peça $=$ teoria; prática/vivência $=$ encenar; cenário/palco $=$ diferentes realidades escolares; diferentes públicos = alunos; ator $=$ professor .

Quando as alunas objetivam os 'saberes da prática', o abstrato se torna concreto na medida em que o professor é comparado a um ator em um palco. A ancoragem parece estar no modo de fazer de ambos, supondo que o professor, assim como o ator, representa um roteiro, algo definido previamente. Esse argumento é idêntico ao de Comenius: 
o professor como organista que executa uma partitura que não saberia escrever. A palavra do professor é como a tinta, a prensa é a disciplina, o modo ordenado de realizar as ações. A comunicação é unidirecional: do ator/professor/organista para a plateia que é passiva, recebe a comunicação. Dessa maneira, a didática deve ser uma didacografia, em que a cabeça do aluno é como uma folha de papel em branco sobre a qual se inscrevem os caracteres, que são os conhecimentos (MAZZOTI, 2008).

Por essa via fica explícito que a metáfora comeniana do ensino como um procedimento predeterminado e determinável, em que a ordem no fazer permite a sua efetividade, opera coordenando e condensando as metonímias anteriores: ensinar é inscrever o correto na cabeça dos alunos; o correto encontra-se nos livros didáticos autorizados, aos quais o professor/ator anima, dá vida. A ancoragem ou sustentação (garantias argumentativas), nesse caso o modo de fazer, é uma concepção ou teoria do conhecimento que informa a teoria de ensino, o empirismo de Francis Bacon. A objetivação, a coisificação, a reificação, se expressa nos símbolos: ator/organista/pianista como símbolo de professor ou ensinante.

Apesar da especificidade do GF 3, a análise dos quatro GFs é importante para refletirmos sobre o curso de Pedagogia. Todos eles retratam como os alunos desse curso estão percebendo sua formação ao se expressarem sobre suas práticas cotidianas, ações, reações, atitudes e comportamentos. A análise GF 3 mostra que os grupos formados, e/ou o curso, podem influenciar de forma diferente nas representações compartilhadas pelos alunos, eventualmente mudando conceitos e valores associados à relação entre teoria e prática.

Pudemos verificar que no GF 3 houve menos dicotomia porque uma parte das estudantes expressou que teoria e prática são intrínsecas, não podendo estar dissociadas na elaboração dos saberes da prática. Tal afirmação repõe claramente o lugar da teoria: se ela é necessária para atuar bem, então o ator não deixa aparecer em sua ação a teoria que ele realiza. Dizendo de outra maneira, um artista/técnico bem formado, que aprendeu corretamente as razões de seu fazer, realiza seus atos 
sem que a teoria apareça. Pode-se levantar a hipótese de que a indissociabilidade da teoria e da prática é a expressão do ato artístico bem feito, virtuoso. Nessa hipótese, qualquer teoria que se afaste do 'fazer bem feito' é considerada inútil, pois não contribuiria para a formação do ator/professor.

\section{Conclusão}

Os resultados obtidos nos GFs 1, 2 e 4 mostraram que as representações sociais das alunas sobre os 'saberes da prática' se associam aos saberes do animador de auditório, logo não é necessário ser um sábio para ensinar, pois o conhecimento se encontra nos livros didáticos. A escola se apresenta, então, como uma manufatura, uma máquina de ensinar, cujos produtos (mercadorias) são trabalhadores escolarizados e a qualidade do aprendido é avaliada pelo mercado de trabalho.

O livro didático é permutado pela partitura ou pelo texto da peça de teatro, que se supõe capaz de determinar por completo o fazer dos artistas e/ou professores. As metonímias 'professor/ator' e 'aula/roteiro de teatro' estão aninhadas na metáfora comeniana que compara o ensino com a impressão tipográfica, a qual supõe que a palavra "entra na cabeça do outro" e o faz pensar corretamente. Por exemplo, o(a) professor(a) irritado(a) pode dizer: "quantas vezes preciso repetir isso para que você entenda?", supondo que a repetição da palavra, dos exercícios, como se faz em matemática, inscreve/marca as ideias na cabeça dos alunos.

Tal hipótese merece ser melhor investigada: o professor/ator seria análogo ao professor/organista? Se for, ambos seriam coordenados e condensados na metáfora comeniana didacografia? O mesmo poderia ser encontrado na disputa entre os teóricos? Enfatizamos, assim, a importância do debate entre teóricos e professores na formação - no caso a formação baseada em conhecimentos práticos para os conhecimentos teóricos ou a formação em serviço. 


\section{Referências}

AGUIAR, M. A. da S. et al. Diretrizes curriculares do curso de Pedagogia no Brasil: disputas de projetos no campo da formação do profissional da educação. Educação \& Sociedade, Campinas, v. 27, n. 96, p. 819-842, 2006.

ALMEIDA, P. C. A. de; BIAJONE, J. Saberes docentes e formação inicial de professores: implicações e desafios para as propostas de formação. Educação e Pesquisa, São Paulo, v. 33, n. 2, p. 281-295, 2007.

ALVES-MAZZOTTI, A. L.; GEWANDSZNAJDER, F. O método nas ciências naturais e sociais: pesquisa quantitativa e qualitativa. São Paulo: Pioneira, 2000.

ANDRADE, R. R. M. de. Pesquisa sobre formação de professores: uma comparação entre os anos 90 e 2000. In: REUNIÃO ANUAL DA ANPED, 30., 2007, Caxambu. Anais... Caxambu: ANPED, 2007. Disponível em: <http://www.anped. org.br/reunioes/30ra/trabalhos/GT08-3165--Int.pdf〉. Acesso em: 15 abr. 2008.

ANDRÉ, M. et al . Estado da arte da formação de professores no Brasil. Educação \& Sociedade, Campinas, v. 20, n. 68, 1999. Disponível em: <http://www.scielo. br/scielo.php?script=sci_arttext\&pid=S0101-73301999000300015\&lng=en\&n rm=iso >. Acesso em: 20 mar. 2009.

BARDIN, L. Análise de conteúdo. Lisboa: Edições 70, 1977.

BRASIL. Diretrizes Curriculares Nacionais para o Curso de Graduação em Pedagogia. Resolução CNE/CP n. 1, fundamentada no Parecer CNE/CP 3, de 21 de fevereiro de 2006. Reexame do parecer CNE/CP n. 5/2005, que trata das Diretrizes Curriculares Nacionais para o curso de Pedagogia. Brasília, DF, 21 fev. 2006. Disponível em: <http://portal.mec.gov.br/cne/arquivos/pdf/pcp003_06. pdf $>$. Acesso em: 17 jul. 2009.

DUARTE, N. Conhecimento tácito e conhecimento escolar na formação de professores (Por que Donald Schön não entendeu Luria). Educação \& Sociedade, Campinas, v. 24, n. 83, p. 601-625, 2003. 
DURHAM, E. R. Um passo atrás com as Novas Diretrizes Curriculares para o Curso de Pedagogia. O Estado de S. Paulo, Caderno A, p. 2, 6 out. 2006.

GAUTHIER, C. et al. Por uma teoria da pedagogia: pesquisas contemporâneas sobre o saber docente. Ijuí: UNIJUÍ, 1998.

LESSARD, C. A universidade e a formação profissional dos docentes: novos questionamentos. Educação \& Sociedade, Campinas, v. 27, n. 94, p. 201-227, 2006.

LELIS, I. A. Do ensino de conteúdos aos saberes do professor: mudança de idioma pedagógico? Educação \& Sociedade, Campinas, v. 22, n. 74, 2001. Disponível em:<http://www.scielo.br/scielo.php?script=sci_arttext\&pid=S0101$-73302001000100004 \& \operatorname{lng}=$ en\&nrm=iso $>$. Acesso em: 20 fev. 2009.

LIBÂNEO, J. C. Diretrizes curriculares da Pedagogia: imprecisões teóricas e concepção estreita da formação profissional de educadores. Educação \& Sociedade, Campinas, v. 27, n. 96, p. 843-876, 2006.

FRANCO, M. A. S.; LIBÂNEO, J. C.; PIMENTA, S. G. Elementos para a formulação de Diretrizes Curriculares para o curso de Pedagogia. Cadernos de Pesquisa, São Paulo, v. 37, n. 130, p. 63-97, 2007.

JODELET, D. Representações sociais: um domínio em expansão. In: JODELET, D. (Org.). As representações sociais. Rio de Janeiro: EDUERJ, 2001. p. 17-44.

LIMA, L. de O. Treinamento do professor primário: uma nova concepção da escola normal. Belo Horizonte: Editora do Professor, 1966.

MADEIRA, M. Representações sociais e educação: importância teórico-metodológica de uma relação. In: MOREIRA, A. S. P. (Org.). Representações sociais: teoria e prática. João Pessoa: Editora Universitária, 2001. p. 123-146.

MAZZOTTI, T. Investigando os núcleos figurativos como metáforas. JORNADA INTERNACIONAL SOBRE REPRESENTAÇÕES SOCIAIS, 1., 1998, Natal. Anais... Natal: Jornada Internacional sobre Representações Sociais, 1998. p. 1-8. Disponível em: <http://www.mazzotti.pro.br/tarso/Comunicacoes/Entradas/1998/11/25_Investigando_os_nucleos_figurativos_como_metaforas.html $>$.Acesso em: 9 nov. 2010. 
MAZZOTTI, T. Doutrinas pedagógicas: máquinas produtoras de litígios. Marília: Poïesis, 2008.

MOSCOVICI, S. Representações sociais: investigações em psicologia social. Petrópolis: Vozes, 2003.

PERRENOUD, P. A prática reflexiva no ofício do professor: profissionalização e razão pedagógica. Porto Alegre: Artes Médicas, 2002.

RIZZINI, I.; CASTRO, M. R. de; SARTOR, C. D. Pesquisando: guia de metodologia de pesquisa para programas sociais. Rio de Janeiro: CESPI/USU; Editora Universidade Santa Úrsula, 1999. Série Banco de Dados - 6, CESPI/USU.

SAVIANI, D. Pedagogia: o espaço da educação na universidade. Cadernos de Pesquisa, São Paulo, v. 37, n. 130, p. 99-134, 2007.

SCHÖN, D. A. Educando o profissional reflexivo: um novo design para o ensino e aprendizagem. Porto Alegre: Artes Médicas, 2000.

SHULMAN, L. S. The wisdom of practice: essays on teaching and learning to teach. San Francisco: Jossey-Bass, 2004.

TARDIF, M. Saberes docentes e formação profissional. Petrópolis: Vozes, 2002.

Recebido: 21/12/2010

Received: 12/21/2010

Aprovado: 25/01/2011

Approved: 01/25/2011 


\section{Anexo}

Texto fictício em estilo de reportagem

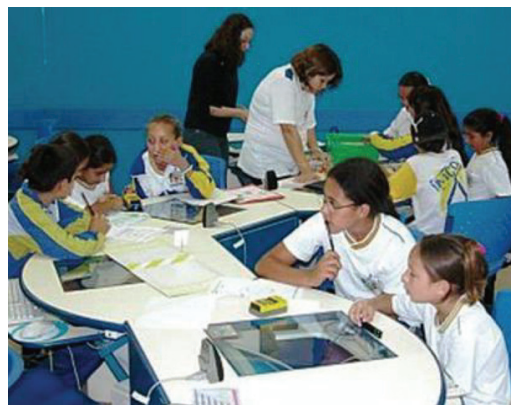

\section{Uma nova formação}

A estudante de Magistério Rosa Barreto participou de um inovador programa de formação de professores. Segundo Rosa, "o programa é uma nova proposta de formação", e a estudante diz ter vivenciado a sua futura profissão no decorrer dos estudos.

De acordo com Rosa Barreto, o programa de formação se constitui em quatro trimestres com 40 horas semanais, distribuídas em cinco dias letivos. Cada trimestre tem 50 dias letivos.

As disciplinas são distribuídas pelas unidades de formação, de acordo com as necessidades apresentadas pelos estudantes. Eles vão a campo para observar, participar e vivenciar situações reais do dia a dia nas diversas instituições educacionais.

- Nós aprendemos a encarar nossa função de professora com amplitude maior do que simplesmente ministradora de conhecimentos, pois participamos ativamente na comunidade e nos tornamos agente social. Nós nos sentimos responsáveis pela mudança da comunidade. Quando falamos de treinamento não é uma mera prática escolar como: plano de aula, de curso e recursos audiovisuais e sim toda a vivência que desejamos ter para ser uma professora. Temos planejamentos de atividades, pesquisa de campo, seminários de estudo, os programas de leitura, os debates sobre problemas educacionais. Tudo, com o objetivo de ir habituando-nos a agir na vida profissional, procurando desenvolver um trabalho profissional - disse Rosa. 
Barreto destaca que as disciplinas são trabalhadas integradas a um problema real. Um exemplo é o tema "Dificuldade de aprendizagem", que serviu como elemento de trabalho de todas as disciplinas, como campo de estágio e de pesquisa nas escolas.

A formação resulta de um treinamento real, precisando que se vivam as situações profissionais reais interpretadas e analisadas à luz das disciplinas.

Para se ter uma ideia geral do projeto, segue um exemplo de participação das disciplinas na realização das unidades de treinamento. A distribuição do tempo escolar fica dessa forma:

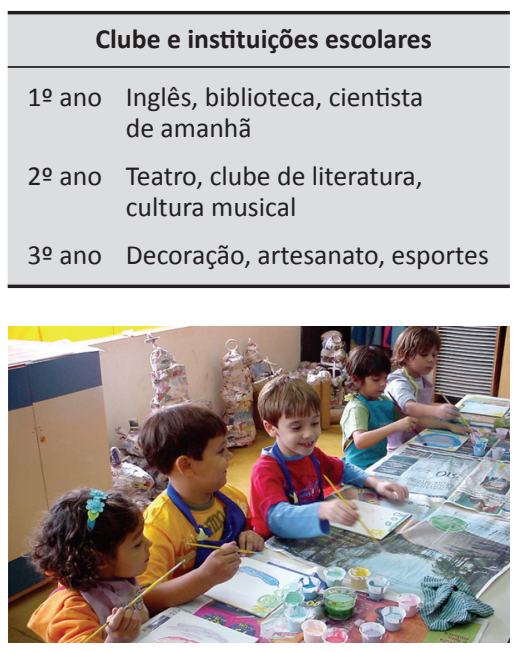

\begin{tabular}{|c|c|c|c|c|c|c|c|}
\hline & emest & & \multicolumn{3}{|c|}{$01 / 03+99$ dias $=100$} & \multirow{2}{*}{\multicolumn{2}{|c|}{$\begin{array}{l}200 \text { dias } \\
\text { anuais }\end{array}$}} \\
\hline \multicolumn{3}{|c|}{ 20 semestre } & \multicolumn{3}{|c|}{$01 / 08+99$ dias $=100$} & & \\
\hline \multicolumn{8}{|c|}{ Semana letiva } \\
\hline & Dom & $2^{a}$ & 3 & $4 \underline{a}$ & 5 & 6a & Sáb \\
\hline 先 & 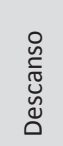 & ร & ร & 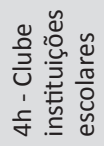 & f & 守 & 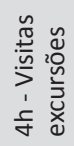 \\
\hline$\frac{0}{\frac{0}{10}}$ & \multicolumn{7}{|c|}{ Estágios, plantão, seminários } \\
\hline \multicolumn{3}{|c|}{$\begin{array}{l}\text { Unidade de } \\
\text { treinamento }\end{array}$} & \multicolumn{3}{|c|}{$\begin{array}{l}\text { Disciplinas isoladas - } \\
\text { orientação do trabalho }\end{array}$} & \multicolumn{2}{|c|}{$\begin{array}{l}\text { Pesquisas } \\
\text { plantão } \\
\text { estágios }\end{array}$} \\
\hline \multicolumn{3}{|c|}{$50 \%$} & \multicolumn{3}{|c|}{$25 \%$} & \multicolumn{2}{|c|}{$25 \%$} \\
\hline
\end{tabular}

Hipótese de duas unidades de trabalho ou unidades de treinamento profissional

(Continua)

\begin{tabular}{lll}
\hline Tema: dificuldade de aprendizagem & Disciplinas & Tema: prédio escolar \\
\hline $\begin{array}{l}\text { Dificuldade específica de } \\
\text { aprendizagem }\end{array}$ & Metodologia & Instalações didáticas \\
$\begin{array}{l}\text { Teste de nível mental e de } \\
\text { personalidade }\end{array}$ & Psicologia da Educação & Pintura e arquitetura \\
\hline
\end{tabular}

Rev. Diálogo Educ., Curitiba, v. 11, n. 33, p. 331-351, maio/ago. 2011 
Hipótese de duas unidades de trabalho ou unidades de treinamento profissional

(Conclusão)

\begin{tabular}{lll}
\hline Tema: dificuldade de aprendizagem & Disciplinas & Tema: prédio escolar \\
\hline Levantamento histórico & História da Educação & História da escola \\
Confecção de boletins & Administração escolar & Planta, circulação \\
Teste de sondagem gráfica & Arte & Decoração \\
Teste de sondagem de nível & Prática de Ensino & Mobiliário \\
& Filosofia da Educação & O espaço escolar \\
Teste de acuidade auditivo-visual & Avaliação na escola & Luz, ar, arborização, carteira \\
Teste de aptidão musical & Música & Acústica \\
Sondagem da precedência social & Sociologia da Educação & Recreios e salas especiais de clubes \\
Índice de desenvolvimento físico & Biologia da Educação & Instalação, alimentação, ed. física \\
\hline
\end{tabular}

Fonte: Dados da pesquisa. 